\title{
DE DOCUMENTOS ETNOGRÁFICOS A DOCUMENTOS HISTÓRICOS: A SEGUNDA VIDA DOS REGISTROS SOBRE OS XETÁ (PARANÁ, BRASIL)
}

Na metade do século passado, os Xetá (conhecidos também como Setá, Chetá, Hetá, Aré e Ñadereta), grupo indígena de língua tupi-guarani, fragilizado demograficamente e violentado de diferentes maneiras, teve consolidado ${ }^{\mathrm{I}} \mathrm{con}$ tato com os brancos, na serra dos Dourados, no noroeste do estado do Paraná (Mota, 20I3). Por meio de envenenamentos, remoção forçada, raptos de crianças e mortes, os brancos, a partir da frente cafeeira que adentrou o território do grupo, fizeram com que os Xetá sucumbissem nos primeiros anos de contato efetivo. Loureiro Fernandes, naquela ocasião - entre o final da década de I940 e início de 1960 - estimou que a população do grupo havia sido reduzida em mais de $70 \%$. Os eventos em torno do contato com os Xetá foram veiculados abundantemente pela imprensa escrita nacional e internacional, chegando mesmo a merecer matéria de página e meia em uma edição da Time do início de I959, na seção Science - trazendo a informação de que se tratava dos "últimos índios da idade da pedra".

Diante da tragédia, José Loureiro Fernandes e Vladimir Kozák tiveram um papel fundamental ao participar, na segunda metade da década de I950, de expedições para encontrá-los, ao cabo das quais ofereceram os primeiros registros e impressões sobre o grupo recém-contatado. Ambos também acionaram diversas redes internacionais para fazer com que a notícia do violento contato com os Xetá se difundisse. A partir da amizade com o casal Robert Carneiro e Gertrude Dole - que Kozák conhecera casualmente em um voo da Força Aérea 
Brasileira (FAB) para o Xingu, em I953 (Benetti, 2016: I75) -, a notícia do contato com os Xetá chegou à Unesco, e Alfred Métraux cogitou a possibilidade de visitar o grupo na serra de Dourados. A possibilidade de Alfred Métraux deslocar-se até o Paraná está sugerida na troca de correspondências entre ele próprio, Robert Carneiro e Gertrude Dole, em outubro de i962. A indiferença estatal ao destino dos índios foi bem retratada em uma correspondência de Gertrude Dole a Alfred Métraux quando ainda tentava persuadi-lo a visitar os Xetá. São suas palavras, em outubro de I962: "Incidentalmente, parece que não é preciso solicitar a permissão para o Ministério da Agricultura, através do SPI, para visitar esses índios, visto que os Hetá estão fora do escopo do trabalho do SPI e teoricamente não existem para eles". Embora os compromissos universitários constem como o que impediu a efetivação da visita, não se deve perder de vista o fato de que a morte de A. Métraux, em abril de I963, aconteceu apenas seis meses depois da troca de correspondências com o casal e cancelou aquele que teria sido o maior apoio aos Xetá no meio acadêmico. ${ }^{2}$

Apesar da ampla divulgação do contato dos Xetá com os brancos, nenhuma medida efetiva foi tomada pelos governos federal e estadual a fim de conter a tragédia que então esteve em curso. Difundida e assimilada a ideia de que os indígenas sucumbiam pela falta de resistência imunológica aos vírus que não conheciam, os poucos Xetá que sobreviveram foram dispersados, pelo Serviço de Proteção ao Índio (SPI), para viver em outras localidades, entre os Guarani e Kaingang, que tinham estabelecido contato com os brancos há mais tempo. Consolidava-se assim o pretendido "vazio demográfico" (Mota, 2013) que permitiria a colonização do noroeste paranaense. Não tardou e os Xetá acabaram sendo dados oficialmente como "extintos".

As informações colecionadas pelos pesquisadores da Universidade Federal do Paraná - Kozák como cinetécnico e Loureiro Fernandes como professor de antropologia - são fundamentais para entender o que se passou no trágico enredo que tragou os índios. Interagindo com os Xetá e com seus colonizadores, ambos legaram importantes registros (cadernetas de campo, artigos, cartas, fotos e filmes) etnográficos que, no decurso do tempo, foram se convertendo em registros históricos, dado que permitem marcar seja o contato com os brancos, sejam as direções que tomaram os sobreviventes dos Xetá após a usurpação de seu território.

Vivendo como exilados (Lima, 20I6) desde a efetivação do contato, os sobreviventes da serra dos Dourados assim permanecem até hoje, dado que ainda não obtiveram a demarcação de suas terras. No atual contexto de luta pelo retorno às suas terras, tornaram-se decisivos os antigos registros produzidos pelos dois autores mencionados (além de outros), depositados, principalmente, em duas instituições museais - o Museu Paranaense (MPR) e o Museu de Arqueologia e Etnologia da Universidade Federal do Paraná (MAE/UFPR)³ -, para o encaminhamento de suas reivindicações. Igualmente, foram fundamen- 
tais tais documentos para a produção do texto da Comissão Nacional da Verdade, concluído em dezembro de 20I4, e da Comissão Estadual da Verdade, recém-concluído, com vistas à reparação da história e da memória de diferentes grupos (estudantes, artistas, operários, camponeses e índios, entre outros) que sofreram violências de toda ordem no período militar. ${ }^{4}$

Neste artigo 5 trato dos usos dos documentos produzidos por Loureiro Fernandes e Kozák, ambos falecidos na década de I970 - com intervalo de dois anos, Loureiro Fernandes em I977 e Kozák em I979 -, indicando, sobretudo, as diferenças na forma como fizeram seus registros e, ao mesmo tempo, como esses vêm servindo, aos novos pesquisadores e aos próprios indígenas, para fins políticos: seja com vistas à demarcação do antigo território xetá - processo que ainda não foi concluído pelo Estado -, seja pelo reconhecimento da memória da violência sofrida pelo grupo. Pretendo, assim, detalhar e desenvolver a ideia de Leopold (2008), sobre "a segunda vida" dos registros etnográficos, quando materiais obtidos em campo extrapolam os fins para os quais foram originalmente concebidos. Além disso, secundariamente, pretendo localizar as contribuições de José Loureiro Fernandes à constituição da antropologia no Brasil, que, em meados do século passado, começava a institucionalizar-se. Como será detalhado adiante, Loureiro Fernandes teve papel fundamental (Helm, 2006) na instituição da disciplina no Sul do Brasil e chegou a presidir a Associação Brasileira de Antropologia - foi seu segundo presidente.

Antes de detalhar os propósitos dos materiais reunidos e/ou produzidos por José Loureiro Fernandes e Vladimir Kozák, cabe apresentar os Xetá e, na sequência, seus primeiros etnógrafos.

\section{OS XETÁ}

Os Xetá, último grupo indígena a ser contatado no Sul do Brasil, falantes de uma língua do tronco tupi-guarani, quase sucumbiram diante do avanço desenfreado da frente de colonização cafeeira sobre suas terras no noroeste paranaense em meados do século passado. Avanço que lhes custou suas vidas. Em uma década, I950, foram reduzidos de aproximadamente 200-250 pessoas para 50, de acordo com dados demográficos de Loureiro Fernandes (I959: 3I).

Ainda hoje o fato de os Xetá terem conseguido ocultar-se por tanto tempo surpreende, sobretudo quando se considera que o grupo indígena mais próximo, os Kaingang, têm contato que recua ao século XIX (Amoroso, 20I4). Também não muito distante do território xetá, os Ofaié, localizados na margem direita do rio Paraná, foram oficialmente contatados no início do século XX - meio século antes, portanto, que os Xetá. Como registraram três arqueólogas (Annete Laming-Emperaire, Maria José Menezes \& Margarida Andreatta, I978) que se dedicaram a estudar o trabalho em pedra dos Xetá, "parecia inverossímil" que ainda houvesse, em meados do século passado, grupo indígena sem contato efetivo com os brancos no Paraná; mas fato é que havia. 
O sucesso em ocultar-se chegou, entretanto, ao fim. Apesar de bastante móveis, entre o final da década de r940 e o início da seguinte, os Xetá foram cercados pelos brancos que avançavam sobre suas terras e então, pouco a pouco, pequenos grupos familiares se foram aproximando das fazendas que começavam a se estabelecer na região. Alguns documentos indicam que buscavam a aproximação para saciar a fome, pois, cercados, não conseguiam satisfatoriamente ter acesso aos recursos naturais, aos animais de caça e pesca. A frente de colonização cafeeira expunha os índios ao porvir dramático que se iniciava.

Do que é possível saber, principalmente a partir de Kozák (s/d), no manuscrito "A história dos Hetá", aparentemente redigido para publicação, foram os agrimensores de uma companhia de colonização, a Companhia Colonizadora Suemitsu Miyamura Ltda, no final da década de I940, os primeiros a dar notícia do contato que se tornaria irreversível. Conforme relata Vladimir Kozák, foi Wismar Costa Lima Filho, funcionário do SPI quem recebeu, em julho de I949, o comunicado sobre a presença dos Xetá nas imediações das áreas de trabalho da colonizadora.

Daí em diante organizam-se algumas expedições para contatar os Xetá, todas elas pouco planejadas, na avaliação de Kozák (s/d), resultando na consecutiva falta de sucesso e adiando o contato definitivo que, àquela altura, se tornava inevitável.

Para a efetiva invasão e usurpação do território xetá, puseram-se em prática estratégias e técnicas violentas que resultaram na ocultação da existência dos Xetá, submetidos ao avanço dos pioneiros. Em pouco mais de uma década, desfez-se uma sociedade da qual se tinham notícias esparsas.

A dispersão dos poucos sobreviventes xetá entre diferentes famílias ${ }^{6}$ e em diferentes localidades foi seguramente resultado de uma conjunção que em nada os favoreceu: o avanço das companhias colonizadoras, que, a partir de métodos violentos, removeu os Xetá de seu território, somado à omissão do órgão responsável pela tutela dos índios - o SPI e, em seguida, a Funai -, que não implementou qualquer iniciativa para conter as investidas dos colonizadores nem para garantir a proteção ao território e à vida dos Xetá. No fim das contas, havia uma implicação mútua, pois a manutenção do domínio sobre seu território era condição para que pudessem dignamente conduzir suas vidas.

A população xetá, acuada diante dos colonizadores, em menos de uma década sucumbiu diante da violência e de diversas mortes, decorrentes de doenças ou envenenamentos, raptos e desaparecimentos, sendo que todos esses termos se confundiam numa trama sinistra. Assim, na documentação restam ainda vários desaparecimentos possíveis de ser identificados na menção a caminhões que se diz saírem da região da serra dos Dourados carregados com diversos xetás, mas que iam adiante com destino incerto. O paradeiro desses xetás que foram dali retirados é completamente desconhecido: raptados e jamais retornados. De forma um tanto enigmática, porque as autoras não indicaram suas fon- 
tes, as três arqueólogas mencionadas (Laming-Emperaire, Menezes e Andreata, I978) anotaram que quem quisesse saber mais sobre os Xetá, deveria procurá-los no Mato Grosso (atual Mato Grosso do Sul), para onde teriam sido deslocados e, em suas palavras, "onde não passam de refugiados".

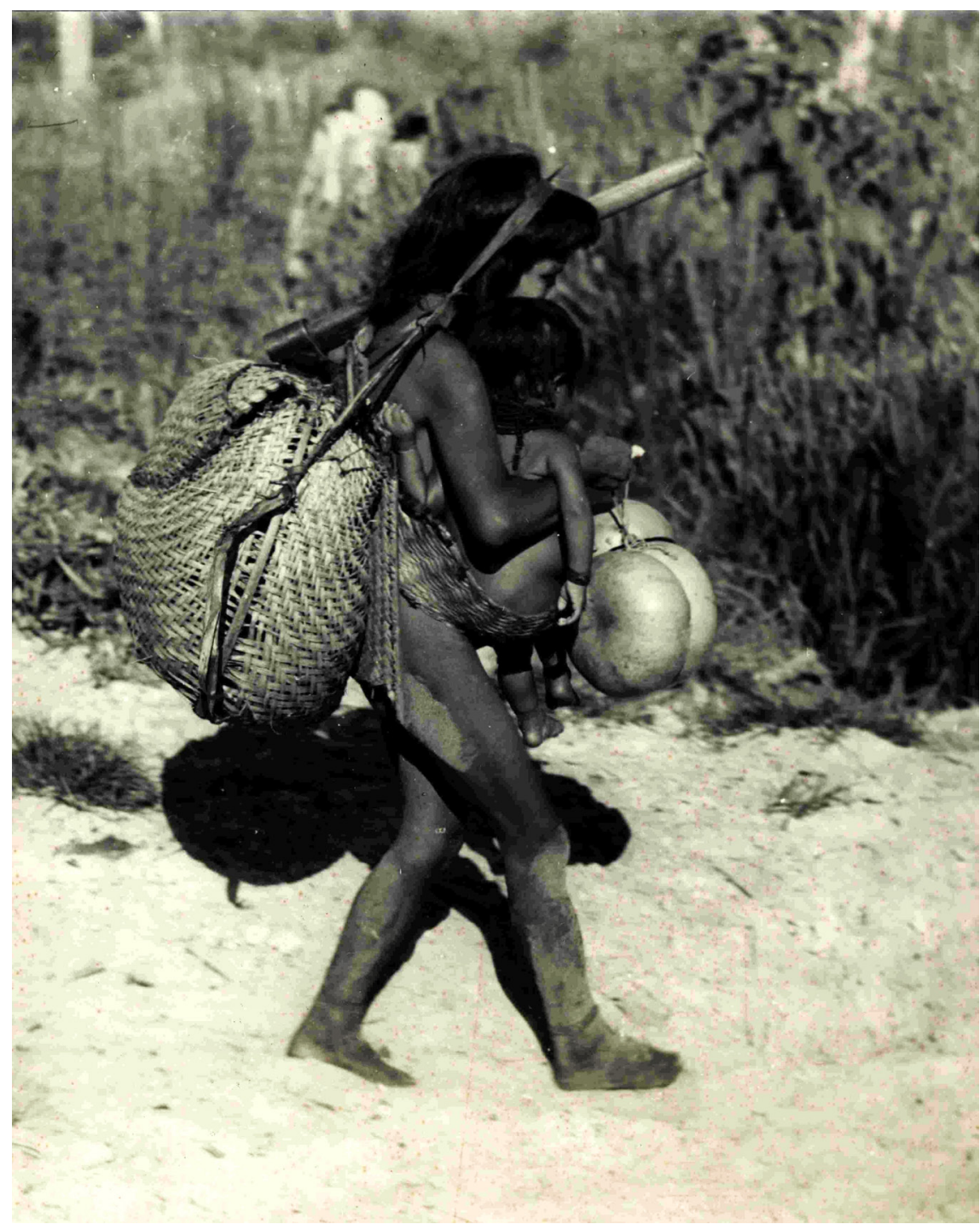

I Mulher xetá com criança Foto de Vladimir Kozák Acervo do Museu Paranaense 
Pondo de lado a falta de detalhamento da informação das arqueólogas, não deve passar sem atenção a palavra escolhida para dizerem da situação em que se encontravam: como "refugiados". De modo direto, o dicionário Houaiss define "refugiado" como aquele que "se retira para um lugar em que haja segurança, para proteger-se" ou como alguém que "se resguarda", que se "expatria" em busca de proteção. Em qualquer possibilidade, trata-se de alguém que tem furtado seu chão, sua vida. Para qualquer lugar que tenham ido, fato objetivo é que do grupo que se descolou - forçadamente ou não - não se teve mais notícias. E a tragédia se avolumou. Do lado dos próprios xetás que sobreviveram à usurpação de suas terras e que permaneceram em suas imediações ou não tão distantes delas, é dito que são não "refugiados", como registram as arqueólogas, mas que teriam sido "extraviados". Foi como "extraviados" que Tuca - no filme Xetá, de Fernando Severo, realizado em 2006 - definiu o que lhes ocorreu: "Extraviou tudo nós, né? Extraviou nós tudo”. A mesma palavra foi repetida por Claudemir de Souza, sobrinho de Tuca, à Comissão Estadual da Verdade oito anos depois, em 20I4. Servindo-nos de qualquer uma das palavras - seja a das arqueólogas, seja a das lideranças xetá -, o que sobressai é a violência de toda a situação, da usurpação da terra e da vida em nome de algo que não os incluía; ao contrário, supunha a sua inexistência.

Em meados de I950, o líder da equipe da UFPR nas tentativas de contato com os Xetá, o professor Loureiro Fernandes, buscava apoios para desacelerar o confisco do território xetá pelos colonizadores. A partir da leitura de documentos arquivados no Centro de Estudos e Pesquisas Arqueológicas (Cepa) da UFPR, instituição de pesquisa por ele criada em meados de I950, é possível ter a dimensão documental da tragédia e de seus esforços para colocar as autoridades responsáveis em ação, mas também da omissão estatal.

Assim, em 22 de fevereiro de I957, Loureiro Fernandes escreveu diretamente ao governador do Paraná, Moysés Lupion, que então cumpria seu segundo mandato (I956-I960) no governo do estado. Um tanto insatisfeito com todos os encaminhamentos - ou com a falta deles - declarou:

\footnotetext{
Após tomar conhecimento na região de Dourados sobre a atual situação dos índios Setá e ouvir alguns dos nossos correlegionários da Assembleia Legislativa, deliberei dirigir esta carta a Vossa Excelência na qual quero expressar meu desejo de me desligar de qualquer compromisso de colaboração com Vossa Excelência na solução do problema desses pobres índios. [...]

Face a atitude deselegante dos órgãos administrativos do Governo de Vossa Excelência em relação aos direitos dos Setá, em glebas da serra dos Dourados, não voltarei a importuná-lo.
}

Um ano antes, em I9 de março de 1956, o diretor do Museu Paranaense, Frederico Waldemar Lange, certamente a pedido de José Loureiro Fernandes, encaminhou um ofício ao governador Lupion solicitando providências para remediar a situação dos Xetá (Maranhão, 20I4). 
Não deve ser inapropriado notar que a omissão estatal se fazia ainda pior no caso do governo do Paraná, em vista do fato de que José Loureiro Fernandes, como correligionário de Moysés Lupion - ambos eram do Partido Social Democrático (PSD) -, deveria contar com seu apoio para, senão solucionar, ao menos aliviar minimamente a situação dos Xetá.7

A partir de outra frente, Loureiro Fernandes denunciava o que se passava com os Xetá em congressos nacionais e internacionais, como na IV Reunião da Associação Brasileira de Antropologia, em I958, e no Congresso dos Americanistas, realizado em Viena em I960 (Fernandes, I959 e I962).

Ao final, o contexto constituía-se de modo totalmente desfavorável aos Xetá, e são duras as palavras de Vladimir Kozák, o pesquisador-cinegrafista que lhes foi mais próximo e simpático, para descrever o que se passava:

Naquela época, algumas vozes se levantaram em protesto contra a aniquilação da Reserva Florestal do Paraná, que era domínio dos Hëtas. Ninguém deu muita atenção a esses protestos, uma vez que a aniquilação da Reserva Florestal era uma manobra política do próprio Governador e a região da serra dos Dourados transformara-se numa Meca dos posseiros e colonos. Os protestos foram arquivados e o escândalo foi abafado, já que muita gente das altas esferas estava interessada nas terras situadas nas proximidades do rio Ivaí (Kozák, s/d: 6).

Consolidada a usurpação das terras xetá, chegou-se a planejar - aliás, com os esforços de Loureiro Fernandes e outros intelectuais paranaenses - uma área para os estabelecer. Para tanto foi prevista e realizada a demarcação do Parque Nacional de Sete Quedas, oficializado em 30 de maio de I96I, no qual destinavam-se terras aos Xetá. Os sobreviventes, contudo, nunca foram para lá deslocados, e, 20 anos depois, em I98I, o Parque foi extinto, dando lugar, no ano seguinte, à inundação para formar o reservatório da Usina Hidrelétrica de Itaipu (Lima \& Pacheco, 20I7). De modo direto cumpre repetir as palavras do relatório da Comissão Nacional da Verdade: no período da ditadura militar os Xetá foram "jogados no esquecimento" (CNV, 20I4, v. 2, p. 220).

Como uma alegoria (Clifford, I998) do esquecimento em que foram jogados, podemos pensar o caso de Ã (Maria Rosa) e Kaiuá (Antonio Guairá Paraná), crianças na época do contato, que foram retirados de suas terras e passaram a ser deslocados de um lugar para outro, pelos agentes estatais responsáveis pela antiga tutela indígena. No final do ano passado, na Universidade Estadual de Maringá (UEM), consegui acesso a uma antiga documentação do Serviço de Proteção aos Índios, documentos da $7^{\text {a }}$ Inspetoria Regional. Pois bem, qual não é meu espanto ao encontrar o nome de Ã e de Kaiuá em uma pauta escolar, na escola do Posto Indígena Apuracana, em I956. A pauta é formada de cinco colunas: o nome do/a aluna/a, a "tribo" (sic), idade, sexo, comparecimento e aproveitamento escolar. O espanto se dava porque na coluna "tribo" para ambos constava simplesmente a palavra "ignorada". Subitamente, na biografia das duas crianças xetá destacavam-se três momentos: tornaram-se órfãos, 
foram desterrados e, finalmente, já sob a tutela do órgão indigenista, foram tidos como de etnia desconhecida ou "ignorada". Sobre Kaiuá, cabe mencionar que ele foi a primeira criança raptada por funcionários do órgão tutor (Silva, I998: 4), que rapidamente, como se verifica na leitura dos documentos que o próprio órgão produziu poucos anos depois, se "esqueceu" ou não se esforçou para reconhecer sua origem. Em resumo, o SPI, responsável então pela pequena menina, pelo jovem rapaz e pela escola, tornou-os, na documentação escolar, sem etnia. Como se pudéssemos dizer que o avanço da fronteira agrícola, tivesse subtraído suas próprias fronteiras e na pauta em que constavam os nomes das crianças identificadas como kaingang, guarani e nacionais, ambos eram simplesmente "ignorados" - a crueza da palavra expõe bem o que se passava então. De certa forma, é possível dizer que o documento (a pauta escolar) explicita alegoricamente o lugar reservado aos Xetá nos anos recentes, no período militar, como "vestígios" ou "restos" de algo que não existiria mais, contrariando sua efetiva presença e perseverança.

Segundo estimativas dos próprios Xetá (Rafael Pacheco, informação pessoal, 20I7), os descendentes do grupo da serra dos Dourados somam atualmente um pouco mais de 200 pessoas - a maior parte composta por moradores da Terra Indígena São Jerônimo, ${ }^{8}$ e os demais dispersos, principalmente, no meio urbano, nas cidades de Curitiba, Guarapuava, Douradina, no Paraná, e Chapecó, em Santa Catarina. Em São Jerônimo, em meio aos Kaingang e Guarani, a maior parte aguarda a homologação de suas terras, cujo relatório de identificação e delimitação, com 2.868 hectares, nas imediações da cidade de Ivaté, foi publicado no Diário Oficial em 25 de junho de 20I4. A homologação das terras xetá está envolta em fortes disputas, e contra as expectativas de retorno ao seu antigo território pesa a tese do Marco Temporal. ${ }^{9}$ A seguir apresento brevemente os dois primeiros etnógrafos dos Xetá - José Loureiro Fernandes e Vladimir Kozák - para, ao final, tecer algumas considerações sobre os registros que fizeram entre as décadas de I950 e I970, e como esses registros repercutem hoje nos encaminhamentos feitos pelos próprios Xetá e a sociedade civil para reparar os danos sofridos na época do contato. ${ }^{\text {Io }}$

\section{JOSÉ LOUREIRO FERNANDES, MÉDICO E INTELECTUAL}

Filho de portugueses radicados no Brasil, José Loureiro Fernandes nasceu em Lisboa, em I 903, quando seus pais estavam em viagem, o que parece explicar o fato de ter sido registrado no Consulado do Brasil. Estudou na Faculdade Nacional de Medicina do Rio de Janeiro, curso concluído em I927. Seus estudos de especialização - em urologia e em antropologia - foram conduzidos na França.

Em Curitiba exerceu a profissão de médico, aproximou-se da vida acadêmica principalmente pelos estudos de folclore (Furquim, 20I5; Anderson, 2015), tendo chegado a ocupar o cargo de secretário-geral da Comissão Paranaense de Folclore (Vilhena, I 997), e participou ativamente da criação e/ou funcionamento 
de instituições vinculadas a estudos da cultura local (paranaense), como o Departamento de Antropologia (Dean), o atual Museu de Arqueologia e Etnologia (MAE), o Centro de Estudos e Pesquisas Arqueológicas (Cepa), todos na Universidade Federal do Paraná, o Círculo de Estudos Bandeirantes (CEB), o Centro de Estudos Portugueses (CEP) e o Museu Paranaense (MPR), entre outras. Além disso, engajou-se na vida política, foi vereador e secretário de Cultura no governo de Moysés Lupion.

Possivelmente em virtude da intensa e variada atividade institucional e política, ${ }^{\text {II }}$ parte dos escritos de Loureiro Fernandes resta pouco conhecida, pois, excetuado o que foi efetivamente publicado, muito está contido em "ofícios, cartas, relatórios, discursos e artigos não publicados", configurando certa "dispersão documental" (Hoerner Junior, 2003: I3; Chmyz, 2000: 90).

$\mathrm{Na}$ III Reunião Brasileira de Antropologia, realizada em I958 em Recife (PE), José Loureiro Fernandes foi eleito presidente da Associação, encerrando seu curto mandato em julho de I959, quando foi realizada em Curitiba a IV RBA, sendo sucedido por Darcy Ribeiro (Corrêa, 2003).

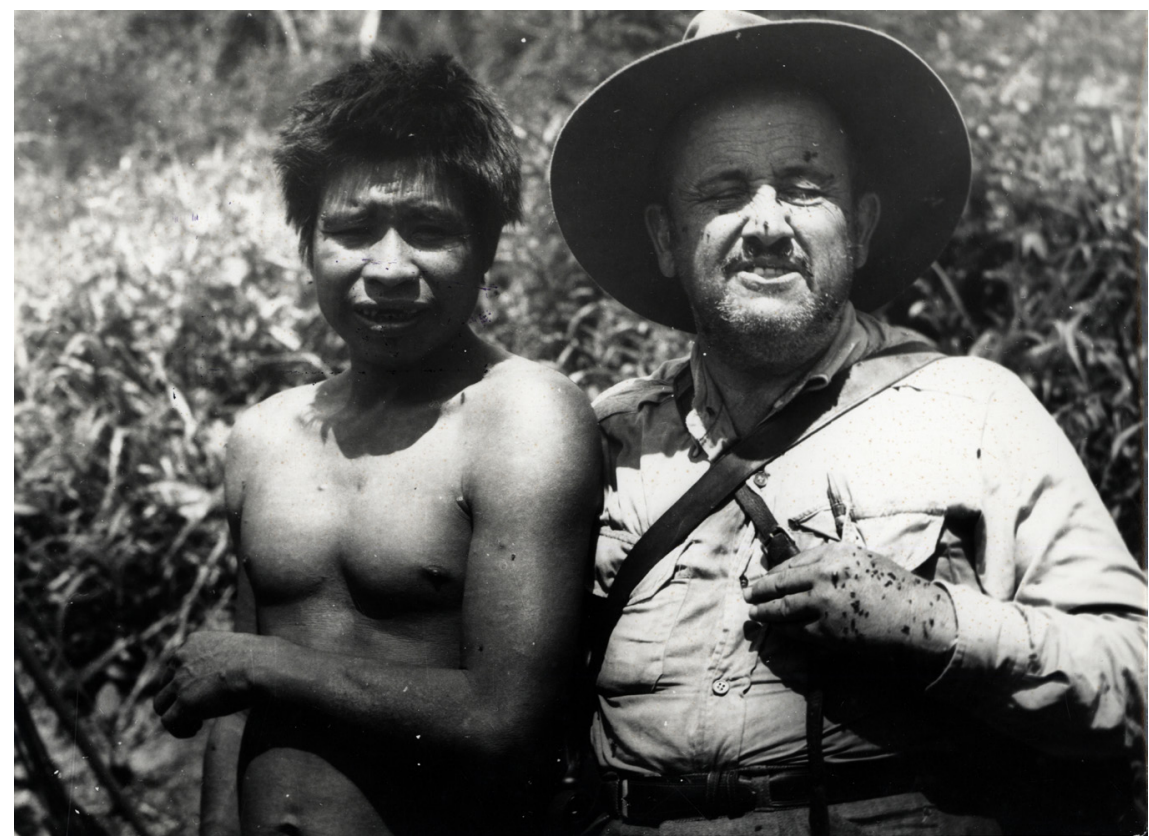




\section{VLADIMIR KOZÁK, “ESTUDIOSO, TÉCNICO E ARTISTA"12}

Em I924, quando tinha 27 anos, V. Kozák (I897-I979), vindo da ex-Tchecoslováquia (atual República Tcheca), chegou ao Brasil e, em I938, estabeleceu residência em Curitiba, após passar por Vitória, Salvador e Belo Horizonte (Carneiro, I98I Rosato, 2009a, 2009b; Benetti, 20I6). Engenheiro de formação, mas tendo estudado também artes plásticas, em Curitiba acabou empregando-se, por intermédio de José Loureiro Fernandes, como cinegrafista na UFPR; e pelas mãos do mesmo professor passou a atuar como voluntário no Museu Paranaense. Entre o final da década de I940 e meados de I960 realizou uma infinidade de expedições de pesquisa, fazendo registros fílmicos e etnográficos sobre populações indígenas localizadas em diferentes partes no Brasil: esteve entre os $\mathrm{Ka}$ maiurá, Karajá, Wauja, Bororo, Kaingang, Guarani e Xetá, ${ }^{13}$ entre outros.

Sem ter constituído família ou deixado herdeiros, após sua morte, o acervo de Vladimir Kozák - que reúne, entre outros objetos, filmes, correspondências, manuscritos, cadernetas pessoais, pinturas e desenhos, totalizando quase 40 mil peças - foi depositado, a partir do esforço de alguns acadêmicos locais (Benetti, 20I6), como herança jacente, no Museu Paranaense e constitui rica fonte de diferentes pesquisas e experiências.

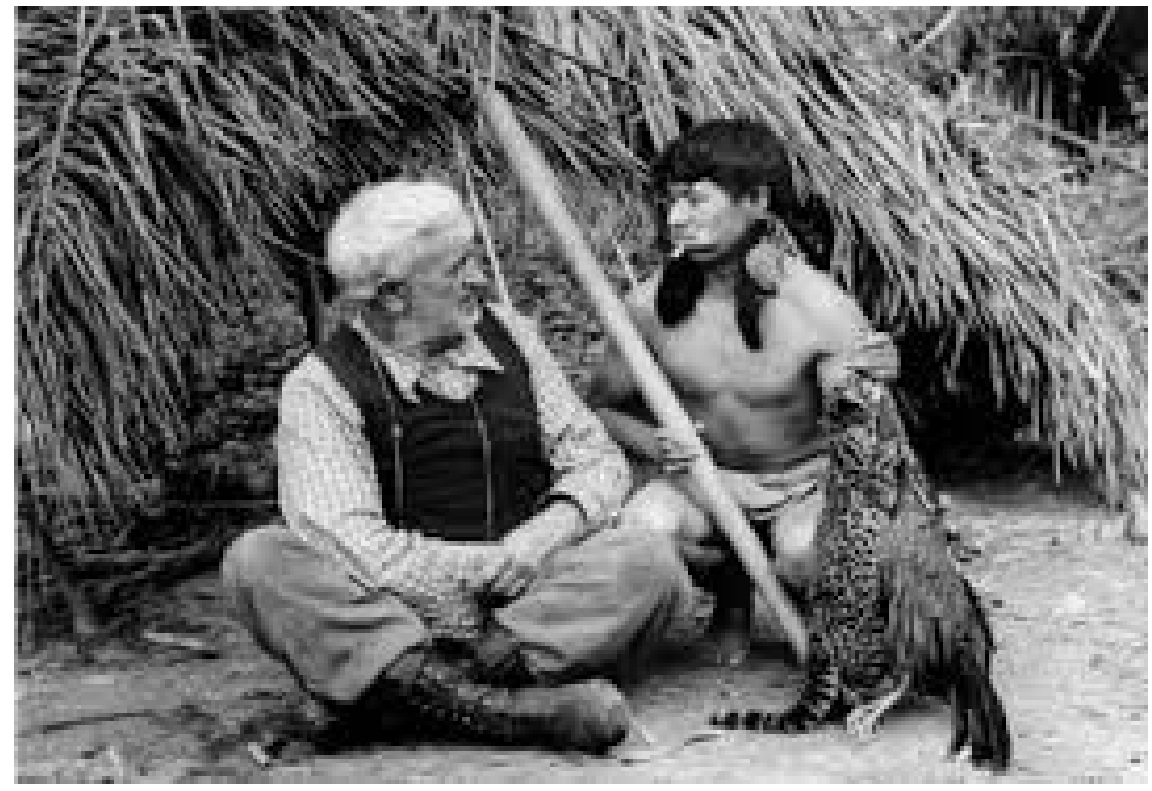

3

Vladimir Kozák e Tuca

Autorretrato de Vladimir Kozák

Acervo do Museu Paranaense 
É importante aqui observar que Kozák não fez planos de doar seu acervo para qualquer instituição. Foi a iniciativa, sobretudo, de dois acadêmicos locais - o arqueólogo Oldemar Blasi e o advogado Edilberto Trevisan - que garantiu o depósito de seus materiais no Museu Paranaense. Segundo Trombini Filho (apud Benetti 20I6: I53), um vizinho de Kozák chegou a indicar que ele não tinha qualquer pretensão de conservar seus materiais, ao contrário: "afirmara que quando se sentisse mal, queimaria a casa e ele próprio, para não deixar para os corvos".

Uma parte menos numerosa do acervo de Kozák, como filmes sobre manifestações populares de moradores do interior do Paraná, está também depositada no MAE/UFPR. À Glenbow Foundation, mantenedora do Glenbow Museum, localizado em Alberta (Canadá), Kozák, em meados da década de I960, vendeu algumas aquarelas, fotografia e artefatos indígenas (Benetti, 2016: 23 I, nota 548). ${ }^{\text {I4 }} \mathrm{A}$ venda de suas coleções, segundo se percebe em correspondências e escritos vários, constituía estratégia pela qual Kozák obtinha recursos para financiar suas pesquisas, fosse para arcar com os custos das viagens, fosse para comprar materiais fotográficos (filmes e lentes, por exemplo).

\section{DE DOCUMENTOS ETNOGRÁFICOS A DOCUMENTOS HISTÓRICOS}

A parceria entre Loureiro Fernandes e Kozák ${ }^{15}$ é facilmente percebida na comunicação apresentada pelo primeiro na III Reunião Brasileira de Antropologia, intitulada "Os índios da serra dos Dourados (os Xetá)". Nela Loureiro Fernandes, antes de detalhar dados etnográficos referentes a assuntos gerais como vestuário e adornos, transporte, preparo dos alimentos, recipientes e armas, apresenta o filme que realizou com Kozák, nos seguintes termos:

\footnotetext{
A nosso ver, um dos méritos dessa comunicação é podermos, graças à organização cine-fotográfica da Universidade do Paraná, trazer a exame dos presentes, em boa técnica Kodak-chrome, cenas da vida extremamente primitiva desse grupo indígena cuja existência era ignorada. Além de ser [um] documentário único no gênero, ${ }^{16}$ pois ao focalizar índios brasileiros em plena cultura lítica, conseguiu registrar um fáceis sobrevivente, do índio da era pré-cabralina* (Fernandes, 1959).
}

Na nota de rodapé que o asterisco indica, Loureiro Fernandes faz saber que as imagens foram captadas por Vladimir Kozák, sob sua instrução, ou, em suas palavras, "sob orientação do autor". De certa maneira, indicando uma posição mais operacional - ou apenas técnica e subordinada (Benetti, 20I6: I04) - do que conceitual do cinegrafista.

Não cabe aqui me estender sobre as tensões na relação entretida entre José Loureiro Fernandes e Vladimir Kozák, explorada por Rosato (2009a) e Benetti (20I6: I03, 20I), mas indicar como seus percursos, embora entrecruzados, são parcialmente divergentes na forma como retrataram os Xetá, grupo que conheceram juntos. Igualmente não convém exagerar as tensões entre ambos. 
Falo isso, mesmo que sem pretender encerrar o assunto, tendo em consideração duas missivas dos personagens aqui abordados: em uma primeira carta, datada de fevereiro de I954 (do acervo do CEB), quando estava em viagem de campo, navegando no rio Araguaia, em direção aos Kayapó, Kozák envia notícias fraternas a Loureiro Fernandes. Numa segunda carta, de I6 de maio de ig64 (do acervo do MPR), Loureiro Fernandes, enquanto diretor do MPR, transfere a Kozák (diretor da Secção de Cinema), temporariamente a direção do Museu por I 2 dias, durante os quais estaria ausente de Curitiba. Dessas correspondências resta claro que, ao menos até meados de I960, ambos pareciam se tratar amigavelmente.

Voltando aos registros que Loureiro Fernandes e Kozák produziram sobre os Xetá, enquanto o primeiro adotava um tom sóbrio e límpido em suas publicações, o segundo insistia em buscar apreender os Xetá por si próprios, a partir de alguma intimidade, retratada em suas fotografias, filmes e pinturas. Em um manuscrito inédito (Kozák, s/d), aparentemente preparado para publicação, disponível no Museu Paranaense, escrito (datilografado) em inglês ${ }^{17}$ provavelmente no início da década de I970, em tom memorialista, pode-se perceber uma escrita mais despojada de Kozák, em contraste com o perfil metódico de Loureiro Fernandes. Provavelmente um dos motivos primeiros para o desentendimento entre os dois, ou pelo menos é o que se tem documentado, é o tempo de permanência na segunda expedição à serra dos Dourados, em I 956. Kozák desejava permanecer mais tempo, temendo não reencontrar o grupo (que ele suspeitava iria embrenhar-se na floresta após a partida da expedição) em outra ocasião, mas Loureiro Fernandes insistiu que deveriam ir embora. ${ }^{18}$ Prevalecendo a decisão do chefe da expedição, partiram e, de fato, como receara Kozák, o grupo não foi reencontrado em ocasiões futuras.

O tom mais despojado - e também, vez ou outra, amargurado - dos registros de Kozák pode ser percebido nas primeiras linhas do manuscrito já mencionado, intitulado "A história dos Hetá":

Agradecimentos, se é que devo fazê-los, são dirigidos aos bondosos indígenas que me permitiram ficar no meio deles enquanto eu trabalhava com minha máquina de filmar. Afora eles, pouquíssimas foram as pessoas que me deram apoio ou me estimularam no trabalho que realizei em prol dos índios (Kozák, s/d).

Poucas páginas depois, Kozák adota um tom mais duro ao criticar a péssima ideia de funcionários do Serviço de Proteção aos Índios que fizeram duas crianças xetá que haviam sido raptadas passar pelo batismo cristão e convidaram como padrinho ninguém menos que o governador do Paraná, Moysés Lupion, bastante implicado na usurpação do território do grupo. Segue o registro de Kozák: 
Nas cerimônias de batismo eles receberam o nome de Caiuá-Guairá e José Tukanambá Paraná. Hoje eles são conhecidos pelos nomes de Kaiuá e Tuka respectivamente. Além de seus novos nomes, receberam do Governador, Sr. Moysés Lupion, uma caderneta para depósitos de poupança... naturalmente, sem qualquer depósito inicial! Em troca disso, perderam as terras que lhes pertenciam porque nelas os seus ancestrais tinham vivido e caçado por centenas e centenas de anos.

De uma certa forma, é como se fosse possível dizer que eles pareciam orientar-se por uma certa imagem convencional - Loureiro Fernandes, do "cientista"; Kozák, do "artista". Ao final, ambos acabaram legando registros fundamentais para que os próprios sobreviventes - seis ainda vivos - e os descendentes dos Xetá possam, nos dias de hoje, encaminhar suas reivindicações, adensando à obra de ambos um sentido político que possivelmente não foi imaginado enquanto desenvolviam seus trabalhos. Pondo de lado suas diferenças, ambos estavam seguros de que registravam a extinção daqueles que acabavam de conhecer.

Kozák assim registrou a amargura de, supostamente, ter sido testemunha do desaparecimento dos Xetá:

São muito limitadas as informações que se tem sobre eles e, antes que qualquer pesquisa aprofundada pudesse ser feita sobre sua raça, desapareceram da face da terra. Muito pouco, portanto, é o que podemos contar. As observações que seguem não têm a pretensão de serem científicas, mas, na medida do possível, são verídicas. Caso alguma informação pareça inverossímil, não será mais possível fazer qualquer verificação ou retificação, uma vez que todos os índios já desapareceram.

E, Loureiro Fernandes (I962), manejando o vocabulário evolucionista, assim se expressou no artigo sugestivamente intitulado "The Xetá - the dying people in Brazil":

Seguramente é um desafio urgente para a antropologia estudar esse pequeno grupo de pessoas, devido à sua forma primitiva de viver, que está fadado a morrer no futuro próximo. Os Xetá têm conseguido sobreviver e preservar sua cultura da Idade da Pedra no extremo noroeste do estado do Paraná, que tem sido intocado pela civilização até a segunda metade do século XX. Mas agora as fronteiras da civilização, avançando pelo Oeste, estão continuamente reduzindo o domínio natural dos Xetá e fazendo sua existência mais difícil. A tribo não conhece a navegação, e assim não é capaz de escapar para longe dos rios Paraná e Ivaí. Esses remanescentes da Idade da Pedra logo estarão diante da civilização da Era Atômica (tradução da autora).

Sem que pretenda esgotar o assunto, destaco que o pendor evolucionista de Loureiro Fernandes é bastante pronunciado em seus escritos sobre os Xetá. Em uma conferência no Congresso Internacional de Geografia, realizado em Curitiba, Loureiro Fernandes (I961:84), definiu, escrevendo em francês, os Xetá como "pobres" e expressou sua convicção acerca de sua condição primitiva: "eles estão em um dos estágios da cultura mais inferiores da humanidade 
atual [...] São caçadores e coletores e vagueiam em pequenos grupos pelas florestas virgens da serra dos Dourados". E arrematou: "sua cultura material é estritamente utilitária".

Considerando que àquela altura o evolucionismo já vivera na antropologia sua derrocada, talvez seja mais apropriado definir Loureiro Fernandes como um "primitivista". Não é o lugar aqui para aprofundar esse entendimento, mas cumpre salientar que a compreensão dos Xetá como "os últimos índios da Idade da Pedra" (Fernandes, I962), distribui-se por toda a literatura relativa ao grupo, apesar de haver, simultaneamente, a compreensão de que estavam em fuga e de que, possivelmente, teriam tido, em tempos anteriores à pressão colonizadora, agricultura e assentamentos maiores (Merencio, 20I4: 43, nota 45). Após Loureiro Fernandes, a ideia de que se estava diante dos "últimos índios da Idade da Pedra" aparecerá em uma publicação da arqueóloga francesa Annette Laming-Emperaire (I964), constando no título de um de seus artigos: Les Xeta, survivants de l'age de la pierre. Anos mais tarde aparecerá também em Kozák (Kozák et al., I98I). ${ }^{\text {I9 }}$

Voltando a tratar apenas de Loureiro Fernandes e Kozák, tudo se passa como se fosse possível dizer que os documentos que produziram entre o final da década de I950 e I970 sofreram propriamente uma transformação, passando de documentos etnográficos a históricos, alcançando novas significações e intenções. É possível dizer que hoje se constituem mesmo como provas jurídicas, sabendo que as fontes escritas têm precedência no Judiciário sobre as fontes orais (Paraíso, I 994). ${ }^{20}$ Tais transformações são dependentes tanto daqueles que manuseiam os documentos, que os fazem reviver, quanto dos contextos em que se inserem. E, nesse caso, sem que seja possível contestar facilmente a autoria e a autoridade (Clifford, I998) das fontes, dado que ambos os autores eram e se tornaram ainda mais conhecidos e prestigiados no meio intelectual local e internacional a partir de suas expedições ao noroeste do Paraná à procura dos Xetá.

$\mathrm{Na}$ atualidade, em que esforços são feitos para que sejam reconhecidos os danos sofridos pelos Xetá, parece possível tomar emprestada a ideia de Nicholas Thomas (I99I) quando diz que "os objetos não são o que foram feitos para ser, mas aquilo em que se tornaram". Se os autores aqui tratados tencionavam fazer o registro etnográfico de um grupo que estaria em extinção ${ }^{21}-$ conforme as citações antes destacadas -, hoje os documentos que produziram atestam justamente o inverso: a sua existência, sem desconsiderar os danos sofridos pelos índios; ao contrário, documentando-os. A "segunda vida" dos documentos acaba, com o perdão do trocadilho, atestando a "vida prístina" entendida aqui, simplesmente, como anterior ao contato sistemático com os brancos - daqueles que foram documentados, isto é, os próprios Xetá, recuperados demograficamente e reivindicando a demarcação de seu antigo território.

Dado o que foi antes afirmado, cabe aqui destacar que essa certificação da "vida prístina" é reconhecida e valorizada pelos Xetá - sobreviventes e descendentes - que, de modo próprio, reconhecem o trabalho dos pesquisadores que estive- 
ram com eles entre as décadas de i950 e I970, valorizando fortemente os registros que produziram. Assim, em meados de 2015, em visita à Terra Indígena Marrecas, nas imediações de Guarapuava, conheci e conversei com Kuen, o mais velho dos sobreviventes xetá do contato na serra dos Dourados. Kuen tem hoje mais de 70 anos e está bastante debilitado fisicamente, com sequelas de um acidente vascular cerebral. Quando estava prestes a retirar-me de sua casa, Helena, sua cuidadora, uma índia kaingang, viúva de Tuca (uma das crianças Xetá raptada e que atuou como intérprete na época do contato), lembrou-se de que tinha guardada uma publicação de Kozák et al. (I98I), o já mencionado "Peixe em lagoa seca". Antes que saísse, Helena apressou-se para buscar o exemplar. Entregou-me em confiança, mas não sem antes olharmos juntos algumas páginas e Kuen me indicar as lembranças contidas nas imagens que ilustram a publicação. Pondo à parte um certo traço anedótico do episódio, a apropriação, política e afetiva, que os Xetá fazem dos registros etnográficos, como documentos que certificam a existência e o vigor da sociedade outrora existente, deve ser destacada.

Aqui faço uma breve digressão para tratar da apropriação que os Xetá têm feito dos materiais etnográficos produzidos sobre eles próprios. Parece-me significativo indicar como tal interesse aproxima-se do caso dos Dogon, no Mali, mencionado por Umberto Eco, em uma bem-humorada conversa com Jean-Claude Carrière (Eco \& Carrière, 20Io). Tal como percebe Umberto Eco, entre os Dogon, Marcel Griaule aparece como o autor da "memória histórica" do grupo, tendo dado impulso a "uma cultura oral determinada pelos livros". Pensando a situação dos Xetá nesses termos, uma "memória histórica" constitui-se a partir dos artigos, objetos e filmes que restaram do período do contato e que se encontram hoje em instituições museais, documentando-os inequivocamente e carregando um forte estatuto de verdade.

A fim de etnografar um tanto mais o que digo, recordo outro episódio recente, ocorrido em maio de 2017 , quando dois filhos de Tikuen ${ }^{22}$ - Dival e Claudemir - estiveram em Curitiba para participar da XV Semana dos Museus, cujo tema, definido pelo Instituto Brasileiro de Museus (Ibram) era Dizer o indizível em museus. Antes que chegassem a Curitiba, Dival e Claudemir solicitaram visitar os acervos relativos aos Xetá no próprio MAE e no Museu Paranaense (MPR). No último foram com um objetivo bastante específico, para o qual me tinham feito antecipadamente portadora do recado com a indicação de seus interesses: queriam conhecer os filmes de V. Kozák, realizados entre os Xetá na década de I96o e que estão lá depositados, mas que não são de acesso público - são originais não editados nem sonorizados de suas filmagens. Em uma manhã assistiram aos filmes de Kozák em uma sala especialmente reservada para os acolher. Visualizadas mais de três horas das antigas películas, agora digitalizadas, perseveraram ainda mais e solicitaram às responsáveis pelo acervo do MPR cópias dos filmes, a fim de que pudessem, junto aos seus, rememorar o passado do grupo - no que foram novamente atendidos. 
O interesse pelas imagens registradas por V. Kozák - nas quais aparecem parentes falecidos de Dival e Claudemir - coaduna também com o plano das lideranças xetá de construir um pequeno centro cultural com a expectativa de receber turistas e divulgar a história e a cultura xetá. Seus esforços direcionam-se assim à formação de seu próprio acervo, que é concebido a partir dos acervos preexistentes - as visitas aos dois museus de Curitiba, indicam esse propósito, embora não se fale, pelo menos até agora, em repatriação dos objetos. Por ora as lideranças xetá têm-se dado por satisfeitas com as cópias - no caso dos filmes -e com as visitas às reservas técnicas dos museus mencionados, nas quais observam em detalhes os objetos (flechas, colares, tembetás e miniaturas de animais em resina, entre outros) outrora elaborados por seus parentes. Não será despropositado apontar que no documentário Jané Rekó Paranuhá, realizado em parceria com pesquisadores da Universidade Estadual de Maringá, os Xetá emulam como deveria ser a vida de seus ancestrais na serra dos Dourados. Os objetos e as imagens (fotografias e filmes) que resultaram das expedições realizadas nas décadas de I950 e I960, constituem seguramente a matriz, por assim dizer, dos esforços contemporâneos das lideranças xetá de pôr em curso sua "revitalização cultural".

Em vez de simplesmente terem documentado a ação genocida, como imaginavam que faziam (e efetivamente fizeram), os registros que Kozák e Loureiro Fernandes produziram acabam servindo, aos pesquisadores e aos próprios Xetá nos anos recentes, para instruir processos que confirmam sua perseverança enquanto grupo culturalmente diferenciado e embasam suas reivindicações políticas - sejam territoriais ou reparatórias. De certa maneira, os usos que são feitos de seus materiais contemporaneamente podem ser inseridos também nas discussões que giram em torno da restituição de dados de pesquisa, ${ }^{23}$ indicando que, mesmo de modo imprevisto e tardio, uma tal restituição é alcançada - e, nesse caso, é seguro que não desagradaria a nenhum dos dois.

Independentemente dos resultados que ainda alcançarão os Xetá em seus propósitos e a "segunda vida" dos materiais elaborados por seus primeiros etnógrafos, resta à antropologia observar como se dá o acesso e a conservação dos materiais produzidos por ambos. Irônica e contraditoriamente, o pesquisador tido como marginal e outsider (Benetti, 20I6: I03), Vladimir Kozák, tem hoje seu acervo pessoal reunido, em sua maior parte, no Museu Paranaense, estando seus escritos (correspondências e cadernetas de campo) e imagens (fotografias e filmes) digitalizados e disponíveis com relativa facilidade aos pesquisadores pela plataforma Pergamum. ${ }^{24} \mathrm{O}$ mais recente reconhecimento veio há pouco, em outubro de 20I7, quando parte do acervo de Vladimir Kozák passou a fazer parte do Programa Memória do Mundo, da Unesco. ${ }^{25}$ Por seu turno, o acervo do acadêmico José Loureiro Fernandes distribui-se de forma fragmentada pelas diferentes instituições que fundou e/ou dirigiu - e não foram poucas - ainda pouco organizado e sistematizado. Receberam tratamento igual ao dos materiais de Kozák apenas os documentos de Loureiro Fernandes disponíveis no MPR. 
Pondo à parte outras possíveis razões, a diferença de tratamento que receberam os materiais produzidos por Loureiro Fernandes e Kozák talvez explique, ao menos parcialmente, por que a obra do segundo tenha até agora merecido maior atenção dos estudiosos (Trevisan, I979; Maranhão, 2006; Rosato, 2009a; Benetti, 20I6). Não deve passar despercebido também o fato de que Loureiro Fernandes, embora tenha sido o segundo presidente eleito da Associação Brasileira de Antropologia, em I959, raramente é mencionado - ou é apenas rapidamente mencionado - nos trabalhos dedicados à história da disciplina como vem sendo desenvolvido pelo menos desde a década de I980 (Melatti, I983; Corrêa, I988; Vilhena, I997). Nos últimos anos, de todo modo, a obra de Loureiro Fernandes começou a ser estudada com mais vagar (Furtado, 2006; Anderson, 20I5; Furquim, 20I5; Guérios, 2017), e certamente a insuficiência de informações e reflexões sobre sua trajetória será ultrapassada.

Finalmente, sem me estender em considerações sobre o estudo da história da antropologia, resta notar que, apesar das diferenças e tensões percebidas entre Loureiro Fernandes e Kozák, dificilmente a contribuição de um pode ser pensada sem a do outro quando se busca a compreensão da trágica história dos Xetá.

Recebido em 20/4/20I7 | Revisto em I8/IO/I7 | Aprovado em 3/II/20I7

Edilene Coffaci de Lima é professora de antropologia da Universidade Federal do Paraná (UFPR) e pesquisadora PQ-2 do CNPq. Na década de I990, cursou mestrado e doutorado em antropologia na Universidade de São Paulo (USP), desenvolvendo pesquisas com os Katukina, de língua pano. Publicou duas coletâneas: Os outros dos outros (20I I), com Lorena Córdoba, e Conhecimento e cultura: práticas de transformação no mundo indígena (20Io), com Marcela Coelho de Souza. Mais recentemente tem pesquisado sobre remoções forçadas de populações indígenas no Brasil durante o período militar. 


\section{NOTAS}

I Há registros sobre a presença dos Xetá no vale do rio Ivaí desde meados do século XIX (Mota, I998).

2 As referidas cartas entre A. Métraux, R. Carneiro e G. Dole, que Kozák recebia em cópias, fazem parte do acervo Vladimir Kozák, e estão depositadas Museu Paranaense.

3 José Loureiro Fernandes ocupa lugar importante na história de ambos os museus (Furtado, 2006). Entre I936 e I947 foi diretor do Museu Paranaense (fundado em I876); fundador do atual MAE/UFPR, foi também articulador da ida de Kozák para contribuir com seus trabalhos em ambas as instituições museais (Benetti, 20I6).

4 Cabe aqui mencionar que colaborei com os trabalhos da Comissão Estadual da Verdade do Paraná, conduzindo a pesquisa bibliográfica e documental e redigindo a parte relativa aos Xetá.

5 Trata-se de uma comunicação originalmente apresentada no painel Terrenos do presente, materiais do futuro: a segunda vida dos materiais etnográficos, no VI Congresso da Associação Portuguesa de Antropologia, de 2 a 4 de junho de 2016 em Coimbra, Portugal, com auxílio do CNPq (Processo 450720/2016-o). Agradeço à direção do Museu Paranaense (Curitiba, Brasil) a cessão das fotos que acompanham este artigo.

6 Não há espaço para detalhar a dispersão dos Xetá, mas cabe observar que algumas crianças foram distribuídas entre funcionários do antigo SPI; outras ficaram com o administrador da Fazenda Santa Rosa; outra ainda foi dada para ser "criada" por um padre, frei Estevão. Naquela ocasião a maioria dos adultos que sobreviveram foi deslocada para a reserva conhecida como Marreca dos Índios, habitada pelos Kaingang e Guarani, nas imediações de Guarapuava. Apenas na última década do século passado é que alguns dos Xetá se fixaram na TI São Jerônimo.

7 Brevemente é preciso mencionar que, aos meus olhos, este parece ser o traço mais contraditório, além de o mais silenciado, da trajetória acadêmico-política de Loureiro Fernandes: ao mesmo tempo em que conhecia a dura realidade dos Xetá - e denunciava a situação mundo afora - participou de um governo bastante implicado na expulsão do 
grupo de seu território tradicional, já que foi secretário de Educação e Cultura na primeira gestão de Moysés Lupion (I947-I95I).

8 Os Xetá da TI São Jerônimo formam a parentela que se estabeleceu ali a partir da chegada de Tikuein, em meados de I989 (Silva, I998: 84). Foi na TI São Jerônimo que aconteceu o primeiro Encontro Xetá, em I994, organizado por professores de antropologia e direito da Universidade Estadual de Londrina (UEL). No referido encontro, reuniram-se 27 xetás, quatro sobreviventes do contato na serra dos Dourados e seus descendentes.

9 O chamado Marco Temporal foi definido, no Superior Tribunal Federal, em meio aos debates da demarcação da Terra Indígena Serra do Sol, e supõe para a demarcação de terras indígenas não o reconhecimento do direito originário, tal como previsto na Constituição de I988, mas a efetiva presença do grupo no território reivindicado em 5 de outubro de I988, data de promulgação da referida Constituição.

Io As obras de ambos os autores têm sido objeto, nos últimos anos, de diferentes pesquisas. No caso de Loureiro Fernandes, remeto aos trabalhos de Maria Regina Furtado (2006), de Bárbara Furquim (2015) e de Anderson (20I5). Há ainda outros trabalhos sobre Loureiro Fernandes, mas são mais laudatórios e menos analíticos (Garcia, 2000 e Hoerner Júnior, 2003). Kozák tem recebido a atenção de diferentes autoras, destaco os trabalhos de Rosato (2009a), Benetti (2016) e Maranhão (2006 e 20I4), sendo preciso ainda mencionar dois filmes de Fernando Severo (I988 e 2006): um sobre o próprio Kozák e outro sobre a luta dos Xetá para reaver parte de suas terras.

I I Cabe notar que não se trata de um "caso isolado". Como notou Mariza Corrêa (I988) essa "múltipla atuação" foi a marca da trajetória dos antropólogos na década de I960.

I2 Definição retirada do filme, o mundo perdido de Kozák, de Fernando Severo. Antes, Kozák já havia sido definido como um artista por E. Trevisan (I979).

I3 Com os Xetá, Kozák esteve, pelo menos, 20 vezes, segundo Carneiro (I98I).

I4 A partir de uma consulta virtual ao Glenbow Museum é possível saber que seu acervo etnológico apresenta artefa- 
tos das etnias carajá, bororo, tapirapé e urubu, grupos, que, como sabemos, efetivamente Kozák visitou. Não é possível, entretanto, precisar se se trata de fato de sua coleção. Disponível em goo.gl/ZzybGd. Consulta em 8 nov. 2016.

I5 Da parceria de Loureiro Fernandes e Kozák restam também objetos (miniaturas de animais moldados em resina, brincos e colares, entre outros) que foram coletados em suas expedições e que compõem o acervo de dois museus: o Museu de Antropologia e Arqueologia (MAE) da UFPR (Perez Gil, 20I2) e o Museu Paranaense (MPR) (Parellada, 20I5).

I6 Loureiro Fernandes faz referência aqui ao documentário Os Xetá da serra dos Dourados, dirigido por ele próprio e com captação de imagens de Vladimir Kozák. Segundo Rosato (2009a: I89), as imagens foram captadas entre I956 e I960.

I7 No MPR está disponível também uma versão em português do mesmo texto, sem que se possa saber se houve um tradutor ou se o próprio Kozák redigiu em português.

I8 Segundo o linguista Aryon Dall'Igna Rodrigues (2005: 59), o retorno apressado da expedição deveu-se a uma "fortíssima reação alérgica às picadas dos mosquitos" que teria acometido Loureiro Fernandes.

I9 Cumpre notar que, supreendentemente, antes de aparecer em qualquer outro lugar, a menção aos Xetá como "índios da idade da pedra" está dada em um processo (Proc. SPI 2 042/56), assinado por Dival José de Souza, da $7^{\text {a }}$ Inspetoria do SPI, em 1956. Para tentar entender essa excepcionalidade, parece-me preciso notar que, em tal processo, que trata justamente da necessidade de que fossem realizadas pesquisas sobre o grupo, pode-se presumir a interferência de Loureiro Fernandes. A menção aos Xetá como os "últimos índios da idade da pedra" aparece também na matéria na revista Time, de I959, mencionada no início do artigo. A genealogia da expressão, aplicada aos Xetá, parece em si mesma merecer uma reflexão.

20 Há aqui certa simplificação, pois são bem mais complexas as relações entre fontes orais e escritas na elaboração de laudos periciais, conforme desenvolvido por Paraíso (I994)

2I Cabe anotar rapidamente que a preocupação com a provável extinção dos grupos indígenas esteve presente em outros lugares do globo. Assim, John Wesley Powell (apud 
Leopold, 2008), fundador do Bureau of American Ethnology em I879, afirmava que era preciso realizar pesquisas etnográficas porque muitas transformações estavam se dando a partir do avanço da colonização. De forma parecida, Morgan, no final do século XIX, apresentava preocupações equivalentes em relação aos iroqueses (cf. Raulin, 20Io), sem esquecer tantos outros autores do século $\mathrm{XX}$, como Malinowski e Lévi-Strauss.

22 Trata-se de mais uma das crianças que foi pega por funcionários do SPI para atuar na atração dos Xetá e que, já adulto, colaborou nas pesquisas de quase todos os acadêmicos interessados em conhecer o grupo: começando por Loureiro Fernandes e Kozák, e alcançando os mais contemporâneos, como Aryon Dall'Igna Rodrigues e Carmen Lúcia da Silva. Tikuen faleceu em 2005, em Brasília, onde estava justamente para colaborar com os trabalhos de Aryon Dall'Igna Rodrigues.

23 A discussão sobre a restituição dos dados de pesquisa há certo tempo se faz no Brasil (Caiuby Novaes, 20I3; Lima, 20I4) e tem lugar também em diferentes países, como a Austrália (Healy, 20II) e a Nova Zelândia (Smith, 2008), entre outros. Na vizinhança latino-americana, os Aché (também conhecidos como Guayaki) no Paraguai, um grupo de língua tupi-guarani - portanto linguisticamente aparentado aos Xetá -, passaram por processos que se assemelham bastante com toda a situação de contato descrita até aqui: o que inclui o rapto de crianças, as doenças, as mortes, a retirada do grupo de seu território em caminhões e, mais recentemente (em 2003), a investigação de sua história, com vistas à reparação, pela Comissión Verdad y Justicia. Na Comissión um vasto conjunto de informações reunidas por prestigiados antropólogos foi fundamental para restabelecer e recontar a história dos Aché, alcançados pela ditadura do general Alfredo Strossner, de I954 a I989 (Parellada \& Beldi de Alcantara, 2008).

24 Trata-se de uma plataforma virtual que visa ao gerenciamento de informações e acervos bibliográficos, concebida pela Pontifícia Universidade Católica do Paraná, com sede em Curitiba.

25 Disponível em <https://goo.gl/5x6W53>, consultado em II out. 2017. 


\section{REFERÊNCIAS BIBLIOGRÁFICAS}

Amoroso, Marta. (2014). Terra de índio. Imagens em aldeamentos indígenas no Império. São Paulo: Terceiro Nome.

Anderson, Gustavo. (2015). Jorge Dias e José Loureiro Fernandes: antropologia e folclore em um debate internacional (1948I954). Monografia (Curso de Ciências Sociais). Universidade Federal do Paraná.

Benetti, Rosalice C. (2016). Vladimir Kozák: sentimentos e ressentimentos de um "lobo solitário". Curitiba: Sociedade de Amigos do Museu Paranaense.

Carneiro, Robert. (I98I). Introdução a Kozák, W. et al. Hetá: peixe em lagoa seca. Boletim do Instituto Histórico e Geográfico Paranaense, Curitiba, XXXVIII.

Caiuby Novaes, Silvia. (2013). A construção de imagens na pesquisa de campo em antropologia. Iluminuras, I3/3I, p. II-29.

Chmyz, Igor. (2000). José Loureiro Fernandes e a arqueologia brasileira. In. Loureiro Fernandes. Médico e cientista. Curitiba: Vicentina, p. II2-I74.

Clifford, James. (1998). A experiência etnográfica - antropologia e literatura no século XX. Rio de Janeiro: Editora UFRJ.

CNV. (20I4). Violação dos direitos humanos dos povos indígenas. In: Relatório da Comissão Nacional da Verdade. Brasília, 2, p. 197-256.

Corrêa, Mariza. (2003). As reuniões brasileiras de antropologia (1953-2003). Brasília: ABA.

Corrêa, Mariza. (I988). Traficantes do excêntrico: os antropólogos no Brasil dos anos 30 aos anos 60. Revista Brasileira de Ciências Sociais, 6, p. 79-98.

Eco, Humberto \& Carrière, Jean-Claude. (20Io). Não contem com o fim do liuro. Rio de Janeiro: Record.

Fernandes, José Loureiro. (1962). The Xetá - the dying people in Brazil. Bulletin of the International Commitee on Urgent Anthropological Research, Vienna, 5, p. I5I-I54.

Fernandes, José Loureiro. (I96I). Le peuplement du Nordouest du Paraná et les indiens de la serra dos Dourados. Boletim Paranaense de Geografia da Universidade Federal do Paraná, 2-3: 79-9I. 
Fernandes, José Loureiro. (I959). Os índios da serra dos Dourados (os Xetá). Anais da III Reunião Brasileira de Antropologia, Recife, Iо a I3 de fevereiro, p. 27-46.

Fernandes, José Loureiro. (I957). Carta enviada ao governador do Paraná Moysés Lupion em 22 de fevereiro. Curitiba: Centro de Estudos e Pesquisas Arqueológicas.

Furquim, Bárbara. (20I5). A história de vida do acervo de cultura popular do litoral paranaense do MAE-UFPR. Dissertação de Mestrado. PPGA/Universidade Federal do Paraná. Furtado, Maria Regina. (2006). José Loureiro Fernandes. O paranaense dos museus. Curitiba: Imprensa Oficial.

Garcia, Antônio. (2000). Dr. Loureiro Fernandes. Médico e cientista. Curitiba: Edição do Autor.

Guérios, Paulo. (2017). José Loureiro Fernandes e os sentidos da atividade intelectual. Comunicação apresentada no evento Produções da Antropologia, UFPR, Curitiba (ms). Healy, Jessica De Largy. (20I I). Pour une anthropologie de la restitution. Archives culturelles et transmissions des savoirs en Australie. Cahiers d'Ethnomusicologie, 24, p. 45-65. Helm, Cecília. (2006). Os 50 anos da ABA no Paraná. In. Eckert, Cornélia \& Godoi, Emilia (orgs.). Homenagens. Associação Brasileira de Antropologia: 50 anos. Blumenau: Nova Letra.

Hoerner Júnior, Valério. (2003). José Loureiro de Ascenção Fernandes. O homem e o meio. Curitiba: Editora Universitária Champagnat.

Kozák, Vladimir. (s/d). A história dos Xetá. Curitiba (ms). Kozák, V. et al. (I98I). Hetá: peixe em lagoa seca. Boletim do Instituto Histórico e Geográfico Paranaense, Curitiba, 38 [texto publicado em I979, originalmente em inglês, pelo Museu Americano de História Natural].

Laming-Emperaire, Annette. (1964). Les Xeta, survivants de l'age de la pierre. Objets et Mondes: La Revue du Musée de l'Homme, 4/4.

Laming-Emperaire, Annette; Menezes, Maria José \& Andreatta, Margarida. (1978). O trabalho da pedra entre os Xetá da serra dos Dourados, Estado do Paraná. Coleção Museu Paulista, série ensaios, 2, p. I9-82. 
Leopold, Robert. (2008). The second life of ethnographic fieldnotes. Ateliers du LESC [on line], 32. Disponível em $<$ https://ateliers.revues.org/3132>. Acesso em I4 dez. 2015. Lima, Edilene Coffaci. (20I6). Exílios índios: sobre deslocamentos compulsórios no período militar. Aceno. Revista de Antropologia, 3, p. 18-35.

Lima, Edilene Coffaci. (2014). Nosso conhecimento vale ouro: sobre o valor do trabalho de campo. Anuário Antropológico / 2013, Brasília, UnB, 39/I, p. 73-98.

Lima, Edilene Coffaci \& Pacheco, Rafael. (2017). Povos indígenas e justiça de transição: reflexões a partir do caso Xetá. Aracê. Direitos Humanos em Revista, 4, p. 219-24I.

Maranhão, Maria Fernanda. (20I4). Índios, negros e caiçaras: etnografia e imagem na etnografia paranaense entre as décadas de I940 e I950. O ideário patrimonial, 2, p. I84-219. Maranhão, Maria Fernanda. (2006). Contextualizando imagens paranistas (I940-I950): o filme etnográfico de Vladimir Kozák e as ciências sociais no Paraná. Monografia (especialização em história e geografia do Paraná). Faculdade Padre João Bagozzi.

Melatti, Júlio César. (1983). A antropologia no Brasil: um roteiro. Série Antropologia, Brasília, 38.

Merencio, Fabiana T. (20I4). Tecnologia lítica xetá: um olhar arqueológico para a coleção etnográfica de lítico lascado e polido do MAE-UFPR. Dissertação de Mestrado. PPGA/Universidade Federal do Paraná.

Mota, Lúcio Tadeu. (2013). Os Xetá do vale do rio Ivaí - I8401920. Maringá: Editora da UEM.

Mota, Lúcio Tadeu. (1998). Os índios Xetá na província paranaense (I853-I889). Pós-História. Revista de Pós-Graduação em História, 6, p. I75-189.

Paraíso, Maria Hilda B. (I994). Reflexões sobre fontes orais e escritas na elaboração de laudos periciais. In. Silva, Orlando Sampaio et al. (orgs.). Perícias antropológicas em processos judiciais. Florianópolis: Editora da UFSC, p. 4I-52.

Parellada, Alejandro \& Beldi de Alcantara, Maria de Lourdes. (2008). Los Aché del Paraguay: discusión de un genocídio. Copenhague: IWGIA. 
Parellada, Claudia. (20I5). Memórias e acervo xetá no Museu Paranaense: diálogos entre antropologia, arqueologia e educação patrimonial. Comunicação apresentada no GT Antropologia dos Objetos, Patrimônios e Museus no I Seminário de Etnologia e Museus. Curitiba: Programa de Pós-Graduação em Antropologia da UFPR.

Perez Gil, Laura. (20I2). O acervo etnográfico do MAE-UFPR. In: Cury, Marília Xavier; Vasconcellos, Camilo de Mello \& Ortiz, Joana Montero (orgs.). Questões indígenas e museus: debates e possibilidades. São Paulo: ACAM Portinari: Museu de Arqueologia e Etnologia da Universidade de São Paulo, p. Io3-I I2.

Raulin, Anne. (2010). Sur la vie et le temps de Lewis Henry Morgan. L’Homme, I95-I96, p. 225-246.

Rodrigues, Aryon Dall'Igna. (2005). Reminiscências de Loureiro Fernandes, Arqueologia, 3 (número especial Anais do Seminário Comemorativo do Centenário de Nascimento do Prof. Dr. José Loureiro Ascenção Fernandes - 1903-2003), p. 53-62.

Rosato, Márcia. (2009a). Uma constelação de imagens: a experiência etnográfica de Vladimir Kozák. Tese de Doutorado. PPGS/ Universidade Federal do Paraná.

Rosato, Márcia. (2009b). Vladimir Kozák e suas imagens. In: Oliveira, Márcio \& Szwako, José (orgs.). Ensaios de sociologia e história intelectual do Paraná. Curitiba: Editora da UFPR.

Silva, Carmen Lúcia. (1998). Os Xetá: sobreviventes do extermínio. Dissertação de Mestrado. PPGA/Universidade Federal de Santa Catarina.

Smith, Linda Tuhiwai. (2008) [1999]. Decolonizing methodologies. research and indigenous peoples. 2. ed. London \& New York: Zed Books Ltd \& University of Otago Press.

Thomas, Nicholas. (I99I). Entangled objects. Exchange, material culture and colonialism in the Pacific. Cambridge: Harvard University Press.

Trevisan, Edilberto. (I979). Vladimir Kozák (I897-I979), o "braide pemegare" dos Borôro. Boletim do Instituto Histórico, Geográfico e Etnográfico Paranaense, XXXVI, p. 9-30.

Vilhena, Luis Rodolfo. (I997). Projeto e missão. O movimento folclórico brasileiro, I947-I964. Rio de Janeiro: Funarte/FGV. 
DE DOCUMENTOS ETNOGRÁFICOS A DOCUMENTOS HISTÓRICOS

596

\section{Filmografia}

Fernandes, José Loureiro. Os Xetá da serra dos Dourados. serra dos Dourados. Departamento de Antropologia da UFPR, [I96-].

Mota, Lúcio Tadeu et al. (eds.). Jané Rekó Paranuhá. Documentário Xetá. 20I0-20I2. LALI/UEM. 2013.

Ribas, Ana Lúcia. O extermínio dos Xetá. Universidade do Paraná (Unipar), 2004.

Severo, Fernando. Xetá. WG7BR Audiovisual, 2006.

Severo, Fernando. O mundo perdido de Kozák. Embrafilme, I988. 
Palavras-chave

Xetá;

Loureiro Fernandes;

Kozák;

documentos;

museus.

Keywords

Xetá;

Loureiro Fernandes;

Kozák;

documents;

museums.

\section{DE DOCUMENTOS ETNOGRÁFICOS A DOCUMENTOS HISTÓRICOS: A SEGUNDA VIDA DOS REGISTROS SOBRE OS XETÁ (PARANÁ, BRASIL)}

\section{Resumo}

Na metade do século passado, os Xetá, grupo indígena de língua tupi-guarani, violentado de diferentes formas, teve consolidado o contato com os brancos, na serra dos Dourados, no noroeste do estado do Paraná. Naquela ocasião, José Loureiro Fernandes e Vladimir Kozák, pesquisadores da Universidade Federal do Paraná, realizaram expedições ao local e legaram importantes registros (cadernetas de campo, artigos, filmes e correspondências) sobre o grupo recém-contatado. Neste artigo trato dos usos dos documentos produzidos por ambos, indicando, sobretudo, como vêm servindo, aos novos pesquisadores e aos próprios indígenas, para fins políticos, seja com vistas à demarcação do antigo território xetá - processo que ainda não foi concluído pelo Estado - seja pelo reconhecimento da memória da violência sofrida pelo grupo.

FROM ETHNOGRAPHIC TO HISTORICAL DOCUMENTS: THE SECOND LIFE OF THE ARCHIVES ON THE XETÁ (PARANÁ, BRAZIL)

\section{Abstract}

In the middle of the last century, the Xetá, an indigenous group of Tupi-Guarani speakers that had been subjected to different forms of violence, consolidated contact with the whites in serra dos Dourados, in the northwest of the state of Paraná. On that occasion, José Loureiro Fernandes and Vladimir Kozák, researchers from the Federal University of Paraná, made expeditions to the area, leaving for posterity important records (field notebooks, correspondence, articles and films) about the newly contacted group. In this article I deal with the uses of the documents produced by both, indicating, above all, how they have served new researchers and the Indigenous people themselves for political ends: either toward the demarcation of the traditional territory of the Xetá - a process that has not yet been concluded by the government - or toward the recognition of the violence suffered by the group. 